\title{
The patient-provider relationship and antenatal care uptake at two referral hospitals in Malawi: A qualitative study
}

J Roberts ${ }^{1}$, D Sealy ${ }^{1}$, H Hopp Marshak ${ }^{1}$, L Manda-Taylor ${ }^{2}$, P Gleason ${ }^{1}$, R Mataya ${ }^{1,2}$

1.School of Public Health, Loma Linda University, Loma Linda, California, USA

2. University of Malawi, College of Medicine, Chichiri Blantyre 3, Malawi

Address for correspondence: Dr. J. Roberts University of Mississippi, School of Health Related Professions, Jackson, MS, USA. Tel: (601) 9844670 E-mail:jroberts4@umc.edu

\section{Abstract}

\section{Background}

In post-stroke patients, impairment of quality of life (QOL) has been associated with functional impairment, age, anxiety, depression, and fatigue. Good social support, higher education, and better socioeconomic status are associated with better QOL among stroke survivors. In Africa studies from Nigeria and Tanzania have reported on post-stroke QOL.

\section{Background}

Approximately $90 \%$ of Malawian women attend antenatal care at least once during their pregnancies; however, most mothers first present during months five and six and do not adhere to the World Health Organization's recommended four visits. The objective of this study was to explore the role the patient-provider relationship has on antenatal care uptake.

\section{Methods}

A qualitative study, consisting of interviews with 20 urban pregnant mothers and eight health workers, was conducted from September to December 2014. Two large tertiary care hospitals in the Central and Southern regions of Malawi were selected as study sites.

\section{Results}

Several factors influenced antenatal care attendance. Significant barriers reported included the patient-provider relationship, clinic wait times, family and friend support, distance from home to the clinic, transportation, cost, and number of visits. The patient-provider relationship appears to have a large impact on antenatal clinic participation. Mothers indicated that health workers often mistreat or demean them during visits. Additionally, health workers revealed that, due to staff shortages, patients often do not receive the care they deserve.

\section{Conclusions}

The results of this study suggest that, in addition to other factors, healthcare provider attitudes influence antenatal clinic attendance. Improving the patient-provider relationship may increase antenatal clinic attendance and decrease pregnancy complications during pregnancy. Professional development opportunities and quality improvement programmes are would help improve patient care and health outcomes while the continued staff shortages in the country are addressed.

\section{Introduction}

Antenatal care (ANC), also known as prenatal care, is routine preventive care offered to expectant mothers to aid in the development and delivery of a healthy child and decrease maternal mortality ${ }^{1}$. The World Health Organization (WHO) developed a focused antenatal care model (FANC), which recommends a minimum of four ANC visits for women with low-risk pregnancies living in developing nations ${ }^{2}$.

Globally, fewer than half of the world's mothers attend the recommended four or more ANC visits ${ }^{3}$. The greatest disparity in antenatal attendance is seen among the least developed countries, primarily in sub-Saharan Africa, compared to industrialized countries. While sub-Saharan Africa has adopted the WHO model, the continued promotion of antenatal care attendance and utilization has been difficult. Although some countries have reported high $(>90 \%)$ ANC attendance rates, these numbers may be misleading; attendance is often reported as at least one visit during pregnancy, not the recommended four ${ }^{4-7}$

As in most sub-Saharan countries, high maternal mortality (574/100,000 women), low child survival (146/1,000 children), and mother-to-child HIV transmission are health challenges in Malawi ${ }^{8}$. According to Malawi's 2010 Demographic and Health Survey, most mothers (95\%) received ANC services from a skilled attendant-either a

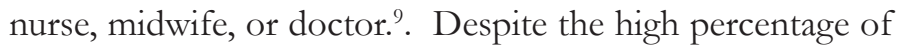
mothers who saw a skilled attendant and the adoption of the WHO's recommend four ANC visits in Malawi's ANC guidelines, only $46 \%$ of mothers had four or more ANC visits. Statistics show that only $12 \%$ presented in their first trimester, 48\% during months four and five, and 38\% in month six or later. Thus, there is still considerable room for improvement in compliance with the revised WHO recommendations, and a need to better understand why compliance continues to remain low.

In sub-Saharan Africa, three-quarters of women attend ANC at least once during their pregnancy, but only onethird of those women meet the WHO recommendations. Two challenges that sub-Saharan Africa faces with ANC are the delay of antenatal care among pregnant women and the lack of adherence to the WHO recommendations. Factors that affect ANC attendance vary by country, region, culture and population. The most common barriers worldwide are transportation, the cost of services, and parity (number of births per mother). However, among sub-Saharan African mothers, age, parity, attitude of caregivers, long wait times, agriculture work, attitude regarding pregnancy and fear of witchcraft are some of the most common barriers reported in the region.

While there have been numerous studies in sub-Saharan Africa exploring perceptions and factors influencing ANC uptake, few have been conducted in Malawi that focus on the patient-provider relationship as a causal factor in delaying antenatal care. ${ }^{10-12}$. Healthcare workers' compliance, perception, and attitude play a crucial role as regards to utilization of FANC. Mathole et al. explain that a poor attitude of health care providers towards pregnant women contributes to low utilization of FANC services in Zimbabwe. They further contends that many of these mothers prefer to deliver with unskilled birth attendants in the villages ${ }^{10}$. Conrad et al. substantiated this finding in a multicentre study conducted in Tanzania, Uganda, and Burkina Faso, where it was noted that health care workers did not comply with the procedures stipulated in FANC guidelines, and this had a tremendous effect on the utilization of FANC ${ }^{11}$. Conversely, Yengo refuted the claim that health workers' (nurses') perceptions affect implementation and utilization of FANC in Tanzania ${ }^{12}$. She argued that health care workers perceive FANC as beneficial both to the pregnant mother http://dx.doi.org/10.4314/mmj.v27i4.6 
and the unborn, but rather a shortage of human and material resources impede successful implementation. We aim to discuss how the patient-provider relationship influences a pregnant woman's decision to seek antenatal care.

\section{Methods}

A qualitative study was conducted at two tertiary care hospitals located in large urban areas in Malawi: Kamuzu Central Hospital in Lilongwe, Central Region, and Queen Elizabeth Central, in Blantyre, Southern Region. Two hundred pregnant women and 20 health workers were approached about participating in the study; of which 20 mothers and eight health professionals agreed. Many of the ANC clients refused consent to participate after hearing what the study was about because they were concerned about their information being kept confidential. Many were concerned that if they were open up about the health workers and practices at the hospital, the information would be shared with the health workers or on the radio. All pregnant women, aged 18 to 49 years, who either attended antenatal care or delivered their baby at the study sites were eligible to participate. Health professionals working in the antenatal clinic, antenatal ward, or labour ward at the study sites were eligible to participate. Data were collected until saturation was achieved. Women who participated in the study represented both paying and non-paying patients. Of the 20 mothers who agreed to participate, 12 were paying, and eight were non-paying (referral) patients.

We used purposive sampling techniques, with the assistance of a gatekeeper, to recruit participants. We were initially prepared to recruit women through ANC clinics and delivery wards. However, the hospitals' tracking systems of patients from each clinic to the antenatal wards, through to the labour wards and postpartum care, proved unreliable. It was difficult to identify women who delivered at the study sites but received late or no ANC during pregnancy. The women we were able to identify from the labour wards refused to participate. Therefore, all 20 mothers who participated in the study were recruited from the hospitals' ANC clinics only. Mothers were identified at the hospitals during ANC clinic hours. Identified mothers were prescreened to ensure they met the inclusion criteria, and their health passports were reviewed to verify ANC attendance. Ten women from each hospital were recruited. Mothers' interviews were held in a designated room at the study sites, during their antenatal visits so the mothers did not have to schedule a separate trip to participate.

Each interview utilized an interview guide, was conducted in the interviewee's language of choice (English or Chichewa), and lasted approximately 45 minutes. A brief demographic survey was conducted at the end of the interview. Interviews were audio-recorded and research assistants took detailed notes during the interviews. Data were transcribed verbatim and coded by the research team, according to apparent themes, using three methods: descriptive, topic, and analytic coding. ${ }^{13}$. NVivo (Version 10; QSR International Pty Ltd., Doncaster, Victoria, Australia) qualitative software was used to store the data and assist in the coding process. Data were triangulated across three areas: data sources (participants), methodology (interviews, observations), and investigators (the research team). Ethical approval for the study was received from Loma Linda University and the University of Malawi, College of Medicine Research and Ethics Committee (COMREC).

\section{Results}

Fifty percent of the pregnant women were between the ages of 30 and 39 years, and $40 \%$ were aged 20 to 29 years. Most women were unemployed (55\%), and the highest level of education attained by $45 \%$ of the women was secondary school. Eighty percent of the women interviewed had a previous pregnancy, $55 \%$ of mothers were in their third pregnancy at the time of the interview, but $33 \%$ had no living children. Most women (75\%) first presented for antenatal care in their second trimester. The sample of health professionals was a diverse group of professionals (physicians, midwives, clinical officers), with $50 \%$ of workers having worked five years or less in the antenatal care field. Tables 1 and Table 2 present detailed information on the study participant demographics.

\section{Table 1: Demographic characteristics of pregnant women who participated in the study}

\begin{tabular}{|c|c|c|}
\hline Characteristic & $(\mathrm{N}=20)$ & $\%$ of total \\
\hline \multicolumn{3}{|l|}{ Age } \\
\hline $18-19$ & 1 & 5 \\
\hline $20-29$ & 8 & 40 \\
\hline $30-39$ & 10 & 50 \\
\hline $40-50$ & 1 & 5 \\
\hline \multicolumn{3}{|l|}{ Employment } \\
\hline Currently & 9 & 45 \\
\hline Past 12 months & 11 & 55 \\
\hline \multicolumn{3}{|l|}{ Education } \\
\hline Primary & 3 & 15 \\
\hline Secondary & 9 & 45 \\
\hline Certificate/Diploma & 2 & 10 \\
\hline Advanced Diploma & 2 & 10 \\
\hline College/University & 4 & 20 \\
\hline \multicolumn{3}{|l|}{ Parity } \\
\hline Primagravida & 4 & 20 \\
\hline Multigravida & 16 & 80 \\
\hline \multicolumn{3}{|l|}{ Number of children } \\
\hline 0 & 7 & 33 \\
\hline 1 & 4 & 20 \\
\hline 2 & 8 & 40 \\
\hline 3 & 0 & 0 \\
\hline 4 & 1 & 5 \\
\hline \multicolumn{3}{|l|}{ Number of pregnancies } \\
\hline 1 & 3 & 15 \\
\hline 2 & 3 & 15 \\
\hline 3 & 11 & 55 \\
\hline $4+$ & 3 & 15 \\
\hline \multicolumn{3}{|l|}{ Pregnancy } \\
\hline Planned & 18 & 90 \\
\hline Unplanned & 2 & 10 \\
\hline \multicolumn{3}{|l|}{ ANC presentation } \\
\hline $1^{\text {st }}$ trimester & 5 & 25 \\
\hline $2^{\text {nd }}$ trimester & 15 & 75 \\
\hline \multicolumn{3}{|l|}{ Gestational age at interview } \\
\hline $0-3$ months & 2 & 10 \\
\hline 4 months & 4 & 20 \\
\hline $5-8$ & 9 & 45 \\
\hline $9+$ months & 5 & 25 \\
\hline
\end{tabular}


Table 2: Demographic characteristics of health workers who participated in the study

\begin{tabular}{|c|c|c|c|}
\hline Characteristic & $(\mathrm{N}=8)$ & $\mathrm{n}$ & $\%$ of total \\
\hline \multicolumn{4}{|l|}{ Age } \\
\hline $25-34$ & & 2 & 25 \\
\hline $35-39$ & & 2 & 25 \\
\hline $40-44$ & & 3 & 38 \\
\hline $45+$ & & 1 & 13 \\
\hline \multicolumn{4}{|l|}{ Education } \\
\hline Certificate/Diploma & & 2 & 26 \\
\hline Advanced Diploma & & 1 & 13 \\
\hline College/University & & 5 & 63 \\
\hline \multicolumn{4}{|l|}{ Occupation } \\
\hline Nurse Midwife Technician & & 3 & 38 \\
\hline Registered Midwife & & 1 & 13 \\
\hline Clinical Officer & & 1 & 13 \\
\hline Physician & & 3 & 38 \\
\hline \multicolumn{4}{|l|}{ ANC Experience } \\
\hline $0-5$ years & & 4 & 50 \\
\hline $6-10$ years & & 2 & 25 \\
\hline $11-15$ years & & 2 & 25 \\
\hline
\end{tabular}

Overall, participants noted many reasons influencing their decision to present for antenatal care. When asked to identify barriers to antenatal care, participants reported patient-provider relationship, long clinic waiting times, lack of family and friend support, the number of visits, transportation, cost, and distance. Figure 1 presents detailed information on the reported barriers. Sixty percent of the participants (mothers and health workers) listed the patientprovider relationship as a reason why women delay seeking care. Mothers indicated that health workers often mistreat or demean them during their antenatal visits. Additionally, health workers agreed that due to staff shortages, patients often do not receive the care they deserve.

While none of the pregnant women interviewed listed the patient-provider relationship as the reason they delayed antenatal care during this pregnancy, it had been a barrier in the past and a reason why they felt their peers currently delay care. The patient-provider relationship was categorized into several themes: treatment at the clinic $(71 \%)$, time spent waiting for service $(50 \%)$, the clinic appointment system $(32 \%)$, cultural beliefs of clinic personnel regarding when to present for care $(89 \%)$, and overall treatment or attitude of the healthcare providers towards the women (71\%).

\section{Clinic Treatment}

Health workers' attitudes and treatment at the clinic was the most reported theme in this section. Participants shared that providers frequently shouted at them. They noted that while it was easier to tolerate the shouting and mistreatment at the clinic, the conditions in the labour wards were unbearable. Women were often in much pain and dependent on the provider for their own and their baby's lives. This was an area participants longed to see improve.

What I would like to see this clinic do is that, when the pregnant mother comes to the clinic at the times she would like to give birth, the doctors should care for the child at appropriate time because sometimes the doctors do shout or beat the patients... So I would love to see the doctors welcoming the patients well....

\section{〜Pregnant Mother \#1 (non-paying patient)}

When asked about the attitudes or treatment of the health workers at the clinic, providers stated that shouting or beating was not a common practice among their peers. However, when asked how women were treated if they attended the clinic late in their gestational cycle, one provider responded with the following:

...of course they attend to the woman but maybe after shouting at ber... they don't send them back. After telling them here and there the right thing to do, they do attend them...

\section{Health Worker \#3 (nurse midwife technician)}

Expectant mothers said the providers' treatment of them amounted to what they believed was a misuse of their authority. This abuse took the form of the tone of voice used in conversation or snide remarks made to mothers regarding their pregnancies. Mothers stated that they felt helpless in these situations as they rely on these professionals for care. Furthermore, since most patients were of a lower socioeconomic status, they feared speaking up or were unsure what to say in those situations.

Sometimes they shout at us and sometimes when you are asking them a question, which you don't know, they think you are so stupid, and you don't deserve to ask them such questions...

$$
\text { Pregnant Mother \#8 (paying patient) }
$$

Sometimes you can meet a very wicked doctor who can slap you, and they can curse at you, and they will tell you I wasn't there when you were getting pregnant, don't put this on me.

> Pregnant Mother \#16 (non-paying patient) 


\section{Health provider attitude}

Health care workers admitted that it was often difficult to maintain positive attitudes throughout the day due to staff shortages. Especially since these hospitals have the responsibility of providing primary, secondary, and tertiary care, the patient load is often greatest at these facilities than at the primary and secondary level. In addition to staff shortages, health workers confirmed that patients were mistreated or shouted at when they presented late for care. A physician discusses how sometimes the mistreatment of patients may be due to the burden and stress of the job in the scenario below.

I think much of it is the personal attitude; it could also be related to the long shift he's doing, he bas one shift and another shift and another shift, and they are tired. (Furthermore), you are telling this woman (what is wrong), and she is not understanding you, and the woman is doing something else and then you yell on top of your voice...

$\sim$ Health Worker \#7 (physician)

\section{Waiting for service}

Women complained that they often waited unnecessarily long for service because the workers worked slowly, took an extended lunch or were conversing among themselves. Clinics at one facility opened at 7:30 am. However, women would arrive at 7:00 am and often wait two or more hours before receiving simple services such as checking vitals, after which they must rejoin the line and wait to see the midwife or the doctor. Women believe the delays were unwarranted, and that health workers did not respect their time.

Sometimes we come to the clinic but the nurses attend to us late and, as a result, we go home late perhaps around six. If we can be starting early — as soon as we come — so that we should be going bome early... I heard that doctors are few; you have to stand on the line for quite a long time waiting for the doctor to come.

\section{$\sim$ Pregnant Mother \#6 (paying patient)}

Health workers agreed that women often endured long waiting times before being seen; they attributed the waiting period, however, to staff shortages. Almost every health worker interviewed stated that the increased number of patients per day and a limited number of staff members made it difficult to see patients in a timely manner.

Well, it depends on how many providers are there. If I am by myself they are here for hours, but if we have a few people helping they are probably here for 3 hours. It gets complicated if we want anything like a urine dipstick or labs the women have to go to different departments in the hospital to get this basic test.

$\sim$ Health Worker \#2 (physician)

\section{Appointment booking date}

All interviewees stated that an appointment booking date was a barrier to receiving timely ANC care. Women needed to book an appointment before a provider could see them. If they were a paying patient (paid out of pocket for services), they would schedule an appointment and return on the given date. Participants reported that women often show up for services only to be given an appointment weeks away. Nonpaying or referral patients also reported having to book an appointment to be seen, though each hospital handled these patients differently. On average, women had to go back to the clinic one month after first presenting for their scheduled appointment date. At one hospital, referral patients had to schedule an appointment to be seen on a specific referral day; all patients referred were seen once per week on the designated referral day. The other hospital treated referral patients as high-risk requiring immediate attention; referral patients presenting for antenatal care were not given booking dates but were incorporated into the day's appointments and seen the same day.

Most women come at around four, five months and... It depends on when they book and how far they are the time they have booked. Because they are booking about twenty-five patients in each initial visit, so if you are coming already late and... the visits are full then, possibly, you will be seen quite late. That's from a clinician's side we can contribute, I think, some harm. From the clients, as well, there are some who want to come and start antenatal early by choice...

Heath worker \#6 (physician)

I wanted to start at two months (October), but the nurses told me that I have to come in November (three months). So because of this I came here and at the reception they told me that I needed to book an appointment, so they told me to come back in December (four months). $\sim$ Pregnant Mother \#12 (paying patient)

\section{Cultural beliefs}

Health workers and pregnant women agreed that cultural beliefs often prevented women from presenting and receiving care. It was common for women to delay ANC because of the cultural belief that a pregnancy should be disclosed only after it is visible. For example, when women presented before their pregnancies were visible, providers who adhered to the cultural belief would turn the mother away, exclaiming "there is nothing there" (pointing to the client's stomach). In addition, if women presented in their early months with proof of pregnancy, health workers sometimes still sent them back, telling them to return when the pregnancy was visible. A health worker explains this practice below.

Yes, it happens in some cases that a woman will report at eight weeks then they (health workers) will say there is nothing when the woman is really pregnant. But what we were supposed to do is that when a woman reports and we have examined her, and we feel there is no pregnancy; I think. we have to do a pregnancy test by urine to confirm that she is pregnant. Because sometimes there is nothing because the fundus is just small, we cannot palpate it, but in real sense that woman is pregnant. We have to confirm with the pregnancy test.

$\sim$ Health Worker \#5 (registered midwife)

Yes, it's true people do say not to tell anyone, but me personally once I know that I have conceived, I will tell my husband and then my relatives. They also say you shouldn't come to antenatal until you are about five months because sometbing has to be visible.

$\sim$ Pregnant Mother \#9 (paying patient)

\section{Discussion}

The health and wellbeing of a patient depend on collaboration between the health provider and the patient. Our results indicate that Malawian urban providers could benefit from intentional collaboration with their patients; currently, patients are reporting feeling fearful, anxious, and refusing to seek care. The patient-provider relationship is an area both mothers and health workers agreed needs improvement. However, both groups view the problem differently-patients blame providers for maltreatment, and poor attitude and service, while providers blame staff 


\section{shortages and systemic barriers.}

Unfortunately, both parties are correct. However, providers have some control and responsibility of the patient's clinic experience. Although they may not have control over staff shortages, workload, or extended waiting resulting from limited staff, each provider is capable of controlling his or her own demeanor, attitude, and treatment of the patient.

The issue of the patient-provider relationship and women's care is a topic that has been discussed by the WHO, the International Confederation of Midwives (ICM) and the International Federal of Gynecology (FIGO). These three institutions noted the importance of a positive patientprovider relationship during pregnancy in their 2004 paper "Making Pregnancy Safer: The Critical Role of the Skilled Attendant"14. They discuss the need for effective communication, interpersonal skills, and a respectful attitude from providers interacting with women during pregnancy.

The White Ribbon Alliance is also concerned about the relationship between providers and women, and they advocate for women's rights, educating women on their rights during the pregnancy period. In their 2011 paper, "Respectful Maternity Care: The Universal Right to Childbearing Women", the alliance highlights seven distinct rights for pregnant women ${ }^{15}$.These rights include freedom from harm and ill-treatment, dignity and respect, and the right to timely healthcare and the highest attainable level of health.

The above organizations confirm that, concerning women's health, the patient-provider relationship is not a new one. Many of the issues raised by participants in this study have been continuously addressed by these organizations on a global level. It is now time to shift from a global response to a national response: the patient-provider relationship in Malawi is a real barrier worth addressing. Research shows that satisfied patients are more likely to adhere to the providers' recommendations ${ }^{16}$. Results from our study indicate that the patient-provider relationship may have negative effects on the patient's experience. We could then infer that a positive patient-provider relationship may yield positive results on the patient's experience.

It would appear that the patient-provider relationship identified in our results improves later in a woman's pregnancy, which is one of the reasons they present late. However, we believe, based on participants' responses, that the relationship might not improve because of the later presentation; the mother who presents late has fewer interactions with the provider during her pregnancy, creating fewer opportunities for negative experiences. This would also partly explain why women are not presenting for the WHO-recommended four ANC visits. In addition, the late presentation of mothers may also be explained by cultural norms that encourage women to seek care when the pregnancy is visible. These norms may initiate late attendance and also contribute to the provider relationship, as they operate within the same cultural milieu. Therefore, the patient-provider relationship may not become better from the second trimester onwards but services may be more readily available to women presenting with a visible pregnancy.

Sixty percent of respondents in our study agreed that patient interactions with providers during ANC visits and labour deterred mothers from frequently attending, if at all. That this finding is contrary to previous studies is likely related to the role the study hospitals serve regarding levels of care provided $^{17-19}$. In Malawi, because of the limited number of healthcare facilities at the various levels of care (primary, secondary and tertiary), the study sites often provide all three types of care, therefore changing the dynamics of roles and responsibilities of providers at these facilities compared to other facilities in previous studies.

There are many barriers to ANC attendance, some of which health professionals cannot control. One factor that health professionals can change is how they interact with patients; by improving the quality of communication, they can help to increase antenatal attendance, which may ultimately reduce complications during pregnancy and improve maternal and infant outcomes.

\section{Conclusions}

A woman's decision to seek ANC is a multifactorial process rooted in several factors, such as transportation, cost, access to care, hospital resources, ANC knowledge, and the patientprovider relationship. In this paper, we focused on the role the patient-provider relationship played in ANC uptake. Our results suggest that healthcare provider attitudes play a pivotal role in influencing antenatal attendance. Improving the patient-provider relationship may increase antenatal attendance and decrease pregnancy-related complications. A combination of methods should be used to encourage women to seek care and do so early. Professional development opportunities and quality improvement programmes would help improve patient care and health outcomes, while efforts continue to address the continued staff shortages and low resources within the country.

The Malawi Ministry of Health has acknowledged that "late and inadequate utilization of antenatal care and low proportion of deliveries by trained health personnel" contribute to high maternal mortality ${ }^{20}$. For this reason, the Ministry should consider placing an emphasis on ways to improve patient-provider relational practices in education programmes. Additionally, providing basic health training and certifications to village and community elders may ease the strain on overworked staff members. Collaborating with elders could be similar to how Health Surveillance Assistants (HSAs) function, as they currently serve in rural areas to provide basic medical care to area residents. Elders may serve alongside HSAs and local health personnel to provide adequate services to women in a timely manner. Through such partnering programmes, more women would have access to healthcare and skilled attendants whom they trust and respect.

Strengths in the study included the use of qualitative methodology to learn more about a topic in a new context. The inclusion of the health workers' perspectives also strengthens the study, as this perspective validated or contrasted what was learned from the maternal subjects. Although the findings of this study provide limited generalizability for non-urban populations, researchers have found similar results in rural areas throughout sub-Saharan Africa. ${ }^{6,10,16,18,19,21}$.

Our results indicate that the patient-provider relationship is an integral part of the decision-making process for the expectant Malawian mother. To improve ANC uptake in this area, measures such as Centering Pregnancy are needed to improve the way women receive care and are treated when they attend clinics ${ }^{22}$. 


\section{References}

1. Ghulmiyyah L, Sibai B. Maternal mortality from preeclampsia/ eclampsia. Semin Perinatol. 2012 Feb;36(1):56-9. doi: 10.1053/j. semperi.2011.09.011.

2. Lawn J, Kerber K, editors. Opportunities for Africa's newborns: practical data, policy and programmatic support for newborn care in Africa [Internet]. Cape Town: The Partnership for Maternal, Newborn \& Child Health (PMNCH); 2010 [cited 2013 Jan 4]. Available from: http://www.who.int/pmnch/media/publications/oanfullreport.pdf.

3. United Nations Children's Fund (UNICEF). Maternal and newborn health: The State of the World's Children 2009 [Internet]. New York: United Nations Children's Fund (UNICEF); 2008 [cited 2013 Nov 19]. Available from: http://www.unicef.org/sowc09/docs/SOWC09FullReport-EN.pdf.

4. Anya SE, Hydara A, Jaiteh LE. Antenatal care in The Gambia: missed opportunity for information, education and communication. BMC Pregnancy Childbirth. 2008 Mar 7;8:9. doi: 10.1186/1471-2393$8-9$.

5. Stekelenburg J, Kyanamina S, Mukelabai M, Wolffers I, van Roosmalen J. Waiting too long: low use of maternal health services in Kalabo, Zambia. Trop Med Int Health. 2004 Mar;9(3):390-8.

6. van Eijk AM, Bles HM, Odhiambo F, Ayisi JG, Blokland IE, Rosen $\mathrm{DH}$, et al. Use of antenatal services and delivery care among women in rural western Kenya: a community based survey. Reprod Health. 2006 Apr 6;3:2.

7. Waiswa P, Kemigisa M, Kiguli J, Naikoba S, Pariyo GW, Peterson S. Acceptability of evidence-based neonatal care practices in rural Uganda - implications for programming. BMC Pregnancy Childbirth. 2008 Jun 21;8:21. doi: 10.1186/1471-2393-8-21

8. National Statistical Office. Malawi MDG endline survey 2014, key findings. Zomba, Malawi: National Statistical Office; 2014.

9. National Statistical Office \& ICF Macro. Malawi demographic and health survey 2010 [Internet]. Zomba, Malawi, and Calverton, Maryland, USA: NSO and ICF Macro; 2011 [cited 2013 Nov 6]. Available from: http://www.nsomalawi.mw/index.php/publications/ malawi-demographic-and-health-survey/2010-malawi-demographicand-health-survey.html.

10. Mathole T, Lindmark G, Majoko F, Ahlberg BM. A qualitative study of women's perspectives of antenatal care in a rural area of Zimbabwe. Midwifery. 2004 Jun;20(2):122-32. doi: 10.1016/j.midw.2003.10.003.

11. Conrad P, Schmid G, Tientrebeogo J, Moses A, Kirenga S, Neuhann F, et al. Compliance with focused antenatal care services: do health workers in rural Burkina Faso, Uganda and Tanzania perform all ANC procedures? Trop Med Int Health. 2012 Mar;17(3):300-7. doi: 10.1111/j.1365-3156.2011.02923.x.
12. Yengo ML. Nurses' perception about the implementation of focused antenatal care services in district facilities of Dar es Salaam. Unpublished Master of Arts thesis. University of South Africa, Pretoria, South Africa; 2009.

13. Morse JM, Richards L. Readme first for a user's guide to qualitative methods. Thousand Oaks (USA): SAGE Publications; 2002.

14. World Health Organization Department of Reproductive Health and Research. Making pregnancy safer; the critical role of the skilled attendant: a joint statement by WHO, ICM, and FIGO [Internet]; Geneva: World Health Organization; 2004 [cited 2015 Jul 17]. Available from: http://whqlibdoc.who.int/publications/2004/9241591692.pdf.

15. The White Ribbon Alliance. Respectful maternity care: the universal rights of childbearing women [Internet]. Washington, DC: The White Ribbon Alliance; 2011 [cited 2015 Jul 17]. Available from: http:// whiteribbonalliance.org/wp-content/uploads/2013/10/Final_RMC_ Charter.pdf.

16. Yakong VN, Rush KL, Bassett-Smith J, Bottorff JL, Robinson C. Women's experiences of seeking reproductive health care in rural Ghana: challenges for maternal health service utilization. J Adv Nurs. 2010 Nov;66(11):2431-41. doi: 10.1111/j.1365-2648.2010.05404.x.

17. Chapman RR. Endangering safe motherhood in Mozambique: prenatal care as pregnancy risk. Soc Sci Med. 2003 Jul;57(2):355-74. doi: 10.1016/S0277-9536(02)00363-5

18. Gross K, Alba S, Glass TR, Schellenberg JA, Obrist B. Timing of antenatal care for adolescent and adult pregnant women in southeastern Tanzania. BMC Pregnancy Childbirth. 2012 Mar 21;12:16. doi: 10.1186/1471-2393-12-16.

19. Ngomane S, Mulaudzi FM. Indigenous beliefs and practices that influence the delayed attendance of antenatal clinics by women in the Bohlabelo district in Limpopo, South Africa. Midwifery. 2012 Feb;28(1):30-8. doi: 10.1016/j.midw.2010.11.002.

20. Ministry of Health, Malawi. National health policy: promoting equity and quality for a healthier Malawi. Unpublished manuscript. Government of Malawi; 2013.

21. Gross K, Armstrong Schellenberg J, Kessy F, Pfeiffer C, Obrist B. Antenatal care in practice: an exploratory study in antenatal care clinics in the Kilombero Valley, south-eastern Tanzania. BMC Pregnancy Childbirth. 2011 May 20;11:36. doi: 10.1186/1471-2393-11-36.

22. Patil CL, Abrams ET, Klima C, Kaponda CP, Leshabari SC, Vonderheid SC, et al. CenteringPregnancy-Africa: a pilot of group antenatal care to address Millennium Development Goals. Midwifery. 2013 Oct;29(10):1190-8. doi: 10.1016/j.midw.2013.05.008. 